\title{
A Review on Current Advances in Crop Productivity, Applications and Impact on Agricultural or Biological Farming
}

Anam Saira ${ }^{1}$, Hafiza Maria Mahmood ${ }^{1}$, Asma Bibi ${ }^{1}$, Sajid Hussain ${ }^{2 *}$, Muhammad Faizan Ullah $^{3}$, Mahnoor Aslam ${ }^{1}$, Muhammad Amjad Farooq ${ }^{4}$

${ }^{1}$ Department Botany, University of Agriculture Faisalabad, Pakistan

${ }^{2}$ Department of Botany, Institute of Pure and Applied Biology, Bahauddin Zakariya University, Multan, Pakistan

${ }^{3}$ Department of Plant Pathology, Faculty of Agriculture, University of Agriculture Faisalabad, Punjab, Pakistan

${ }^{4}$ Institute of Horticultural Sciences, Faculty of Agriculture, University of Agriculture Faisalabad, Pakistan

DOI: $10.36348 / \mathrm{sb} .2021 . v 07 \mathrm{i} 04.005$

| Received: 06.03.2021 | Accepted: 29.03.2021 | Published: 13.04.2021

*Corresponding author: Sajid Hussain

\section{Abstract}

Crop models are a formal way to present quantitative knowledge about how a crop grows in interaction with its environment. One of the possible appliances of remote sensing in farming is the estimation of crop acreage and recognition of crop situation because of either water stress or pest. APSIM model is composed of several modules that enable the simulation of agricultural systems based on plant, animal, soil, climate, and management interactions. As pesticides have various effects on the growth of crops, but the use practical applications of crop modeling plant extracts as the source of weed killers can be very beneficial for plant growth. Although there is a range of crop modeling crops, but sorghum and sunflower are the mostly studied crops effectively controlled by crop modeling. The main theme of agricultural research is very complex and diverse topic involving cooperation and antagonism of various processes in crops. Crop modeling has been a core theme of the agricultural research for controlling the various diseases. So, there is a need to conduct more research on the crop modeling relations of wheat with respect to increase the yield and productivity in order to increase the quality of crops to contribute to the human life.

Keywords: Plant Sciences, agriculture, Crop modeling, traits, crop productions, applications.

Copyright (C) 2021 The Author(s): This is an open-access article distributed under the terms of the Creative Commons Attribution 4.0 International License (CC BY-NC 4.0) which permits unrestricted use, distribution, and reproduction in any medium for non-commercial use provided the original author and source are credited.

\section{INTRODUCTION}

Predictions of crop productions, modeling yield, and crop stress recognition have been determined via remote sensing records. Detection and recognition of plant illness and preparation for efficient manage estimations are important to sustain crop production. One of the possible appliances of remote sensing in farming is the estimation of crop acreage and recognition of crop situation because of either water stress or pest. Vigorous plants provide an elevated reflectance in the near-infrared area and an inferior in the observable area. Illness influenced plants demonstrate an elevated reflectance in the perceptible band and a minor in infrared area. This theory can be employed in discerning vigorous and infected crop [13].

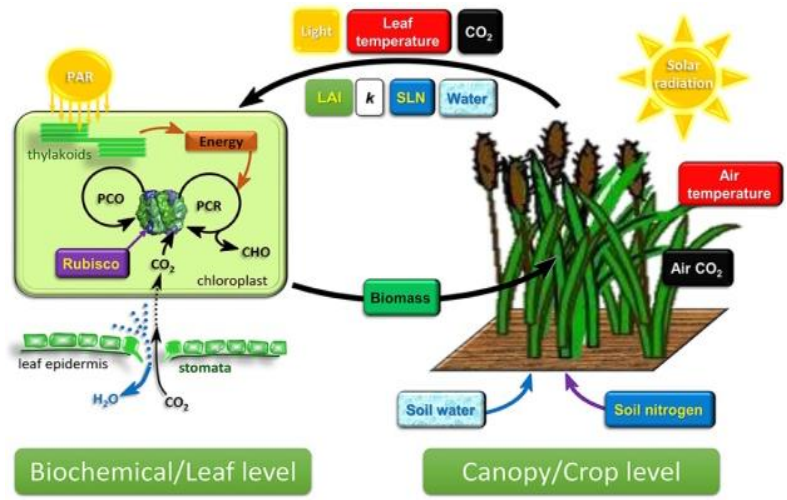

Fig-1: Shows the different factors involved for crop level

APSIM model is composed of several modules that enable the simulation of agricultural systems based on plant, animal, soil, climate, and management interactions. In this case, the framework incorporated APSIM version 7.7 modules for maize growth, soil water dynamics, soil and surface organic matter 
dynamics, and crop management rules. Simulated data of secondary and target traits over the growing season present a useful resource to evaluate the advantages of additional phenotyping of traits at different levels of the trait hierarchy and in contrasting environmental conditions. Intermediate traits can be measured at a single time point, or they can be monitored at multiple time points during the season to describe their dynamics $[3,4]$.

It is a recent concept and these interactions were found to play an important role in the both the natural and manipulated systems as many evidences from previous studies indicates that in the agronomic systems not only biotic components interacts but also there is a diversity of reactions occurring due to the crop modeling chemicals. The interactions between various components of the environment are very important in determine the rate the distribution and abundance of species in the ecosystem. These crop modeling substances if used with logic can have beneficial impact on the crop production systems improving genetic diversity and maintaining stability of ecosystem and nutrient conservation and the most important is the protection of crops from the effects of weeds and pests [5-7].

\section{Role in Agricultural Sciences}

Weeds are very dangerous competitors of crops for water availability and nutrient interactions and also occupying space and affecting the light distribution among plants. These also provide space for the attack of pests on the crops and damage the crops through the release of crop modeling chemicals in the rhizosphere affecting the yield of crops badly. Grain yield of many crops in Pakistan can be accelerated by the removal of weeds from the crops with the accompanying increase in crop yield to about $37 \%$. There are two major factors responsible for the low productivity of wheat (Triticum aestivum L.) in Pakistan. One is the late sowing and second and most important is the infestation of weeds on crops and about $25-30 \%$ of yield losses are due to the infestation of wheat with the weeds [8-11].

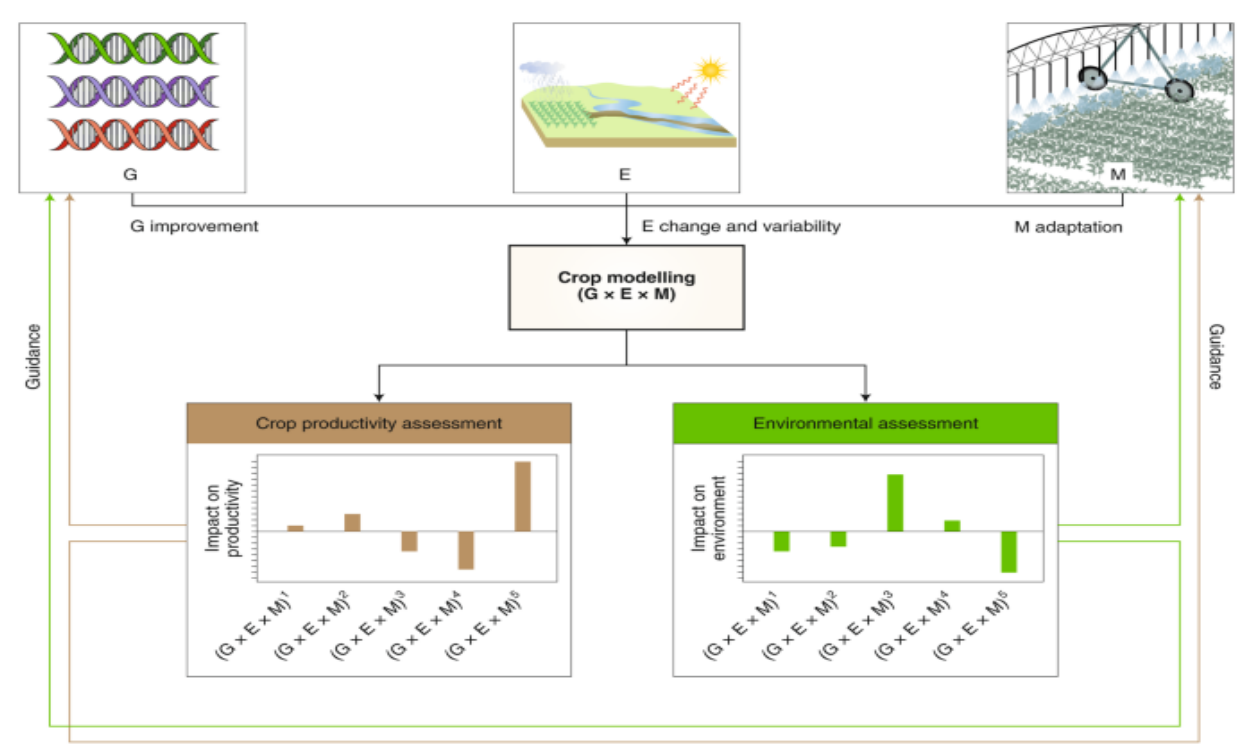

Fig-2: Shows the principles of crop modeling in agriculture

The productivity of wheat in Pakistan can be improved through two means which are use of hybrid technology or genetic breeding and other is the management of tillage operations. For the purpose of achieving sustainable agriculture and ecological development wheat productivity can be improved by using biologically safe ways [12].

The previous literature remains unclear about the application of crop modeling extracts of different crops such as sorghum and sunflower for the removal of weeds from different crops. But there no such work available in the literature which could demonstrate the use of reduced dose of fenoyxyprop-pethyl and bromoxynil + MCPA in combination with water extracts of sunflower and sorghum for controlling the growth of weeds in wheat crop. In fact, these crop modeling chemicals can be used at high concentration for the control of weeds in many crops as natural pesticides $[13,14]$.

At present, the two main areas experiencing increased productivity in relation to wheat are genetic breeding and tillage management. An important aspect involves increasing the productivity of wheat by biologically safe ways in order to achieve sustainable agriculture and ecologic development. At present, the two main areas experiencing increased productivity in relation to wheat are genetic breeding and tillage management. An important aspect involves increasing the productivity of wheat by biologically safe ways in 
order to achieve sustainable agriculture and ecologic development [15-19].

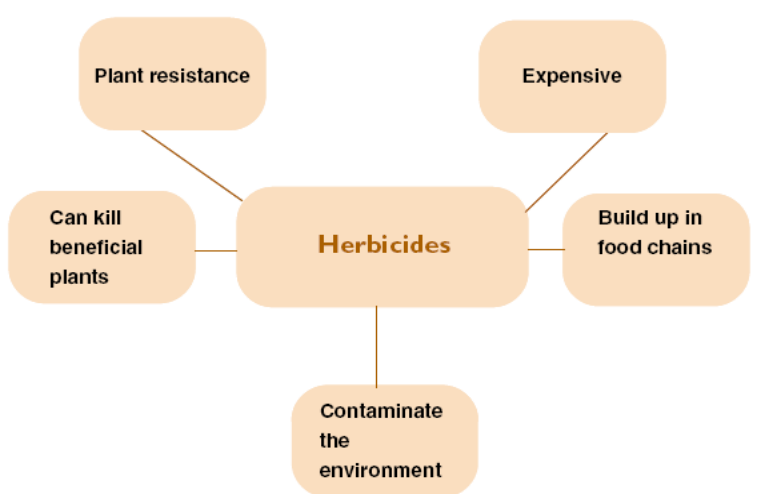

Fig-3: Shows the role of herbicides and its applications in agriculture

As pesticides have various effects on the growth of crops, but the use practical applications of crop modeling plant extracts as the source of weed killers can be very beneficial for plant growth as the application of sorghum extract can reduce weed population to about $95 \%$. So, the use of these crop modeling material can reduce the use of herbicide and is becoming the main research objective in Pakistan [19]. The control of weed as using water extract of sorghum was ranging between $40-50 \%$, which is less than weed control achieved with herbicides $80-100 \%$ $[20,21]$.

Sunflower is also a source of several substances as chlorogenic acid, iso-chlorogenic acid, scopolin and alpha naphathol which can be used as crop modeling chemicals or natural weed killers. The weeds dry weight can be reduced through the application of sunflower extract by $41 \%$ and enhancing the yield of wheat crop through reducing weeds. If wheat is sprayed three times with sunflower extract about 25,35 and 45 days of sowing, then the dry weight of weeds can be reduced up to $70 \%$ as compared to non-sprayed crops [22-24].

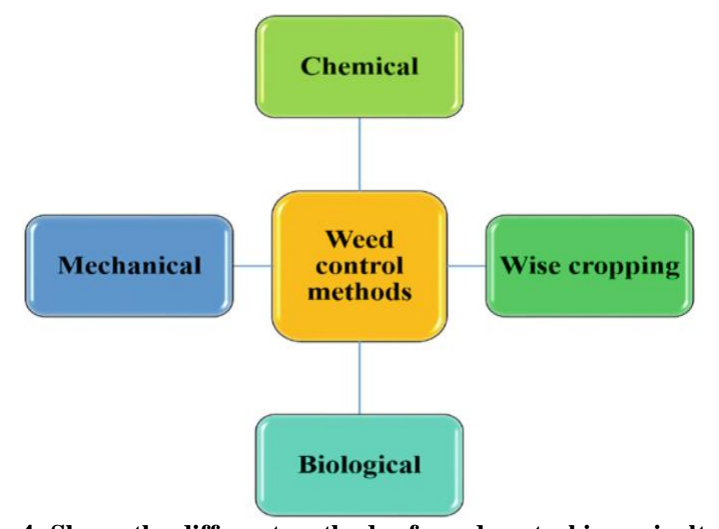

Fig-4: Shows the different methods of weed control in agriculture

The weed control in the agricultural system through the use of chemical and biochemical methods and the impacts of weeds on crops, challenges faced by researcher during management, potential of crop modeling crops and also the use of chemical and biochemical methods for the control of weeds. Here we have discussed some important strategies for controlling weeds as the use of crop modeling crops, intercropping, cover crops and residues and alternative sowing of crop modeling crops [25, 26].

\section{Crop Modeling Crops}

Crop modeling effects to control weeds such as barnyard grasses, sugar beet, pigweed millet and barley etc. and water for the extraction of active compound in plants having crop modeling effects and about 92 plants examined concluding that about ten plants were suitable for the control of weeds due to their low residence time in the soil including cucumber, hogweed, mint and common buttercup etc. Among trees about 80 species have been found to exhibit the process of chemical and biochemical methods [27-29]. Tree species possessing crop modeling chemicals can regulate the germination and growth of other weeds growing in the vicinity of them and variety of chemicals have also been isolated and identified to have crop modeling properties. For example, limousine that controls billy goat weed and Mimosa stated that some wheat cultivars also possess crop modeling chemicals and he studied two durum wheat varieties commonly used in northern Tunisia for their crop modeling effects on the growth of bread wheat and other crops such as barley $[30,31]$.

The process in which one plant secretes some chemicals into the surrounding which are toxic for the growth of some other plant species by the chemicals which were causing toxic effects or growth suppression are called as crop modeling chemicals. During this process crop modelling chemicals are produced as secondary metabolites by plants, microorganisms, virus and fungi etc. and effects badly or suppresses the normal growth process of agricultural and biological systems [32].

Bread wheat (Triticum aestivum L.) is used as food by majority of peoples and cultivated around the world. But it also possesses chemicals which have crop modeling potential. Secondary metabolites are the compound which are produced in all crops and have crop modelling substances such as phenolic, terpenoids, alkaloids, coumarins, tannins, flavonoids, steroids and quinines. The wheat role is considered because of hydroxamic acids and phenolics acting as crop modelling chemicals [32].

Although there is a range of crop modelling crops, but sorghum and sunflower are the mostly studied crops. Sorghum has been used as cover crop during the summer season due to its rapid growth and crop modelling effects on the growth of weeds. The 
Anam Saira et al., Sch Bull, Apr, 2021; 7(4): 93-97

residue of sorghum planted in the spring can reduce $90 \%$ of weed population in crops. The crop modelling chemicals which are released through the root hairs of sorghum include gallic acid, protocateuic acid, syringic acid, vanillic acid, p-hydroxybenzoic acid, p-coumaric acid, benzoic acid, ferulic acid, m-coumaric acid, caffeic acids, p-hydroxybenzaldehyde and sorgoleone which suppresses the growth of weeds in crops [33, 34]

Mulberry also possesses a variety of crop modeling chemicals declining the dry weight of many weedy plants several types of grasses which have been classified as a noxious and the most common weed in the cultivated areas of Africa, Australia, southern Europe, and Asia and it is among the ten dangerous weeds reducing the crop production around the world. Leaf water extracts of mulberry at concentrations of $25 \%, 50 \%, 75 \%$, and $100 \%$ was tested on bermuda grass and wheat were compared with a control (distilled water). The results of the study indicate application of $100 \%$ mulberry leaf water extract before the germination resulted in the complete inhibition of germination in Bermuda grass and wheat [35].

\section{CONCLUSION}

The main theme of agricultural research is a very complex and diverse topic involving cooperation and antagonism of various processes in crops. It has been a core theme of the agricultural research; it has been a complex and variable topic. The modern studies investigating the genetic bases by evaluating every genetic factor which have achieved certain results but still a wide range of problem is yet to be solved. As wheat being used as stable food by majority of world population. So, there is a need to conduct more research on the crop modeling relations of wheat with respect to increase the yield and productivity in order to increase the quality of crops to contribute to the human life.

\section{REFERENCES}

1. Shahid, A., Ali, S., Zahra, T., Raza, M., Shahid, A., Saeed, M. U., \& Javaid, F. Influence of Microbes in Progression of Cancer and DNA Damaging Effects.

2. Iftikhar, A., Shahid, A., Shah, S. S., Ali, S., Raza, M., Ali, E., \& Umbreen, S. Antimicrobial Activities of Selected Medicinal Plant with Potential Role of Chemical Compounds.

3. He, M. Q., Zhao, R. L., Hyde, K. D., Begerow, D., Kemler, M., Yurkov, A., ... \& Kirk, P. M. (2019). Notes, outline and divergence times of Basidiomycota. Fungal Diversity, 99(1), 105-367.

4. South, P. F., Cavanagh, A. P., Liu, H. W., \& Ort, D. R. (2019). Synthetic glycolate metabolism pathways stimulate crop growth and productivity in the field. Science, 363(6422).

5. Kah, M., Tufenkji, N., \& White, J. C. (2019). Nano-enabled strategies to enhance crop nutrition and protection. Nature nanotechnology, 14(6), 532540.

6. Renard, D., \& Tilman, D. (2019). National food production stabilized by crop diversity. Nature, 571(7764), 257-260.

7. Qamar, M., Mustafa, G. A., Tariq, S., Rafeeq, H., Rafiq, M., Naqvi, W. Z., ... \& Kanwal, T. Novel Methods for Detection of Biological Samples, Current Direction and Future Perspectives.

8. Munns, R., Day, D. A., Fricke, W., Watt, M., Arsova, B., Barkla, B. J., ... \& Tyerman, S. D. (2020). Energy costs of salt tolerance in crop plants. New Phytologist, 225(3), 1072-1090.

9. Naeem, M., Hayat, M., Qamar, S. A., Mehmood, T., Munir, A., Ahmad, G., ... \& Hussain, A. (2019). Risk factors, genetic mutations and prevention of breast cancer. Int. J. Biosci, 14(4), 492-496.

10. Shafiq, S., Adeel, M., Raza, H., Iqbal, R., Ahmad, Z., Naeem, M., ... \& Azmi, U. R. (2019). Effects of Foliar Application of Selenium in Maize (Zea Mays L.) under Cadmium Toxicity. In Biological Forum-An International Journal, 11(2), 27-37.

11. Ahmad, I., Khan, S., Naeem, M., Hayat, M., Azmi, U. R., Ahmed, S., ... \& Irfan, M. (2019). Molecular Identification of Ten Palm Species using DNA Fingerprinting. Int. J. Pure App. Biosci, 7(1), 4651.

12. Usman, G., Muhammad, N., Hamza, R., Usman, I., Ayesha, A., Saqib, U., ... \& Fatima, Q. (2019). A Novel Approach towards Nutraceuticals and Biomedical Applications. Scholars International Journal of Biochemistry, 2(10), 245-252.

13. Tahir, M. F., Ali, S., Noman, M., \& Goher, M. A Novel Approach towards the Potential Effects of Chlorpyrifos on Testicular Biochemistry and Physiology of Male Sprague Dawely Rats.

14. Yang, W., Feng, H., Zhang, X., Zhang, J., Doonan, J. H., Batchelor, W. D., ... \& Yan, J. (2020). Crop phenomics and high-throughput phenotyping: past decades, current challenges, and future perspectives. Molecular Plant, 13(2), 187-214.

15. Naeem, M., Ali, J., Hassan, M. Z., Arshad, B., Rao, M. H. I., Sarmad, M. S. K., ... \&amp; Hassan, M. U. (2019). Novel Approach towards DNA Barcoding as a Tool in Molecular Biologyand Biological Activities of Cyclotides with Particular Emphasizes at Molecular Level. In Biological Forum-An International Journal, 11(2), 83-96.

16. Zhang, X., Fang, Q., Zhang, T., Ma, W., Velthof, G. L., Hou, Y., ... \& Zhang, F. (2020). Benefits and trade- offs of replacing synthetic fertilizers by animal manures in crop production in China: A meta- analysis. Global change biology, 26(2), 888900.

17. Reilly, J. R., Artz, D. R., Biddinger, D., Bobiwash, K., Boyle, N. K., Brittain, C., ... \& Winfree, R. (2020). Crop production in the USA is frequently limited by a lack of pollinators. Proceedings of the Royal Society B, 287(1931), 20200922. 
18. Naeem, A., Saddique, S., \& Chand, S. A. (2019). Advancement and Future Directions towards Herbal Treatment for Various Diseases.

19. Zhou, X., Yu, J., Spengler, R. N., Shen, H., Zhao, K., Ge, J., ... \& Li, X. (2020). 5,200-year-old cereal grains from the eastern Altai Mountains redate the trans-Eurasian crop exchange. Nature plants, 6(2), 78-87.

20. Singh, A., Kumari, R., Yadav, A. N., Mishra, S., Sachan, A., \& Sachan, S. G. (2020). Tiny microbes, big yields: Microorganisms for enhancing food crop production for sustainable development. In New and Future Developments in Microbial Biotechnology and Bioengineering (pp. 1-15). Elsevier.

21. Naeem, M., Ashraf, A., Safdar, H. M. Z., Khan, M. Q., Rehman, S. U., Iqbal, R., \& Ahmad, G. (2020). Biochemical changes in patients with chronic kidney failure in relation to complete blood count and anemia. IJB, 16(1), 267-271

22. Zhang, Q., Song, Y., Wu, Z., Yan, X., Gunina, A., Kuzyakov, Y., \& Xiong, Z. (2020). Effects of sixyear biochar amendment on soil aggregation, crop growth, and nitrogen and phosphorus use efficiencies in a rice-wheat rotation. Journal of Cleaner Production, 242, 118435.

23. Naeem, M., Hussain, A., Azmi, U. R., Maqsood, S., Imtiaz, U., Ali, H., ... \& Ghani, U. (2019). Comparative Anatomical Studies of Epidermis with Different Stomatal Patterns in Some Selected Plants Using Compound Light Microscopy. International Journal of Scientific and Research Publications, 9(10), 375-380.

24. Ahsan, M., Aslam, M., Akhtar, M. A., Azmi, U. R., Naeem, M., Murtaza, G., ... \& Shafiq, S. (2019). Effect of inoculation of three rhizobial strains on maize hybrids. Journal of Biodiversity and Environmental Sciences, 14(6), 168-177.

25. Hazafa, A., Batool, A., Ahmad, S., Amjad, M., Chaudhry, S. N., Asad, J., ... \& Ghani, U. (2020). Humanin: A mitochondrial-derived peptide in the treatment of apoptosis-related diseases. Life Sciences, Volume 264, 2021, 118679.

26. Khan, S., Abbas, A., Ali, I., Arshad, R., Tareen, M. B. K., \& Shah, M. I. (2019). Prevalence of overweight and obesity and lifestyle assessment among school-going children of Multan, Pakistan.
27. Rafeeq, H., Ahmad, S., Tareen, M. B. K., Shahzad, K. A., Bashir, A., Jabeen, R., ... \& Shehzadi, I. Biochemistry of Fat Soluble Vitamins, Sources, Biochemical Functions and Toxicity. Haya: The Saudi Journal of Life Sciences

28. Ghani, U., Naeem, M. Bukhari, S. S. H., Yar, G., Tariq, I., Siddique, S., Nawaz, H. A., Pal, Z. A. A., Nasim, F., \& Bukhari, S. A. H. (2019). Prevalence and Risk Factors associated with Hepatitis B and Hepatitis $\mathrm{C}$ and their Correlation with Inflammatory Markers among Southern Region of Punjab. Biological Forum - An International Journal, 11(2): 136-143.

29. Khan, S., Zelle Rubab, S. H., Abbas, A., Arshad, R., \& Tareen, M. B. K. Hematological profile of children with severe acute malnutrition at the Tertiary care hospital in Multan.

30. Muhammad, N., Umair, R. A., Sarmad, A. Q., Ahmad, M., Tariq, M., \& Muhammad, A. F. (2019). Reliable vaccine production by using Risk Based Bioengineering Strategies. 6th International Conference on "Sustainable Agriculture in Changing Climate: Strategies and Management. 261.

31. Rafeeq, H., Arshad, M. A., Amjad, S. F., Ullah, M. H., Muhammad, H., Imran, R. K., ... \& Ajmal, H. Effect of Nickel on Different Physiological Parameters of Raphanus Sativus.

32. Deutsch, C. A., Tewksbury, J. J., Tigchelaar, M., Battisti, D. S., Merrill, S. C., Huey, R. B., \& Naylor, R. L. (2018). Increase in crop losses to insect pests in a warming climate. Science, 361(6405), 916-919.

33. Watson, A., Ghosh, S., Williams, M. J., Cuddy, W. S., Simmonds, J., Rey, M. D., ... \& Hickey, L. T. (2018). Speed breeding is a powerful tool to accelerate crop research and breeding. Nature plants, 4(1), 23-29.

34. Lichtfouse, E., Navarrete, M., Debaeke, P., Souchère, V., Alberola, C., \& Ménassieu, J. (2009). Agronomy for sustainable agriculture: a review. Sustainable agriculture, 1-7.

35. Bøckman, O. C., \& Olfs, H. W. (1998). Fertilizers, agronomy and $\mathrm{N} 2$ O. Nutrient cycling in Agroecosystems, 52(2), 165-170. 